\title{
Design and Development of Educational Robot Teaching Resources Using Artificial Intelligence Technology
}

\author{
https://doi.org/10.3991/ijet.v16i05.20311 \\ Suo Huang \\ Hunan Urban Construction College, Xiangtan, China \\ huangsuo2020@163.com
}

\begin{abstract}
To further innovate English teaching reform and promote the optimization and development of intelligent and innovative English teaching resources, an intelligent educational robot has been developed based on the current vigorous development of artificial intelligence educational robot technology. In addition, a set of educational robot assisted teaching curriculum resources is designed based on the robot, which is applied in primary school English teaching practice, and has achieved good application effect. The research shows that the robot can complete the functions of English vocabulary teaching, role play and free dialogue, and can further improve students' attention and initiative in classroom practice. The results of the questionnaire survey show that the teaching curriculum based on educational robot has higher scores in the completion of teaching objectives, the design of teaching content, the fluency of teaching links and the innovation of teaching process, which is superior to the traditional English teaching. This exploration provides important case data and theoretical basis for primary school English teaching reform, and it is of great significance to further innovate educational resources and promote teaching reform.
\end{abstract}

Keywords-Artificial intelligence; educational robot; English teaching

\section{$1 \quad$ Introduction}

The popularity of Internet and artificial intelligence (AI) technology promotes the intelligent and resource-based development trend in various industries. In this era, the education industry has undergone new changes and development [1]. In the teaching of various subjects, intelligent technology and equipment are widely used in teaching practice, and a good teaching effect is achieved [2]. In the practice of English teaching, it is found that word memory and oral expression are often the two major problems that restrict students' learning in English, which directly affect students' English performance and oral expression ability [3]. In addition, most of the lower grade students are lack of attention and learning initiative, which directly affect the students' attitude and learning effect in class. Relevant studies show that the introduction of AI technology into English teaching can not only improve students' interest in English learning, but also deepen students' memory, enrich their sense of 
context, and improve their English application ability [4]. In the present stage of English teaching, multimedia courseware, educational robot and other intelligent equipment are often used to assist learning. Among them, the research of intelligent educational robot assisted teaching is less popular due to the limitation of technical level, which is a less studied field in the field of English teaching.

At present, with the rapid development of China's intelligent robot industry, robots are used in all walks of life to replace humans to carry out some relatively dangerous and repetitive work, mainly engaged in rescue, guidance, service and other work [5]. In the field of education, the robot also plays a very important role. The educational robot is a kind of intelligent tool to assist learning developed for the education field. The use of intelligent educational robot can cultivate students' creativity, analysis ability and imagination ability [6]. The educational robot can fully mobilize the initiative of students. It has the characteristics of openness, intelligence and good human-computer interaction, which often plays a very prominent role in the teaching activities of lower grade students. In the process of teaching practice, the educational robot can act as a teaching assistant to assist teachers in curriculum demonstration and other related activities, which can greatly improve students' attention and concentration. At the same time, the educational robot can be also used as the student's educational companion, so that learners can learn in the interaction with the robot after class, which fully embodies the idea of edutainment [7].

The educational robot is introduced into English teaching in the middle school. A set of intelligent educational resources based on educational robot is designed. With NAO robot as the development platform, the educational robot realizes the functions of vocabulary teaching, role play and free dialogue. Based on this educational robot, the intelligent curriculum of robot teaching is designed. In the course, the relevant functions of the educational robot are fully used to complete many teaching activities, such as classroom interaction, group discussion, and knowledge carding. In order to further verify the effect of robot assisted teaching, a questionnaire survey is conducted on teachers and students in the school. The results show that most of the respondents believe that robot assisted teaching has a good effect on improving students' enthusiasm and classroom effect. This exploration provides important technical support and case analysis for the follow-up robot assisted teaching research, which is of great significance to the follow-up English teaching related research.

\section{$2 \quad$ Method}

\subsection{Design requirements of educational robot}

Primary school students have poor self-control ability and low learning initiative, but they have strong curiosity and strong desire to learn new things. When robots are used in English teaching, it is necessary to consider the relevant teaching characteristics. Based on the characteristics of primary school English teaching, the intelligent robot can be used in daily teaching and after-school practice. In daily teaching, educational robot can help teachers to teach English vocabulary and other 
related courses. After class, the educational robot can also act as a learning companion. It requires that the educational robot must have the functions of vocabulary practice, role play and intelligent dialogue. In addition, the robot also needs to achieve independent walking, fluent dialogue and other functions to further attract students' attention.

\subsection{Design of educational robot system}

Figure 1 shows the system structure of the educational robot designed. Among them, the NAO educational robot system is a robot operating system developed based on the NAO robot platform, mainly including speech processing, body movements, network communication and other functions [8]. Speech processing includes speech recognition and speech synthesis functions. The robot's body movements can be used to assist speech synthesis to express a series of emotions. The network communication function of the robot system can call the speech function on the server [9]. NAO robot and server complete the main interaction function. NAO robot is responsible for receiving and preprocessing signals and displaying the feedback results of the system. In operation, the robot first receives the user's voice signal. Then, the robot's own processing system converts the sound signal into the text signal, and then calls the corresponding server interface to complete the corresponding function. The internal system of the robot will feedback the call result from the server to the reader through the speech synthesis function and body movement. The server communicates with NAO robot through the interface. The server mainly performs the speech function, and the data generated in the process of program execution is also stored in the server database.

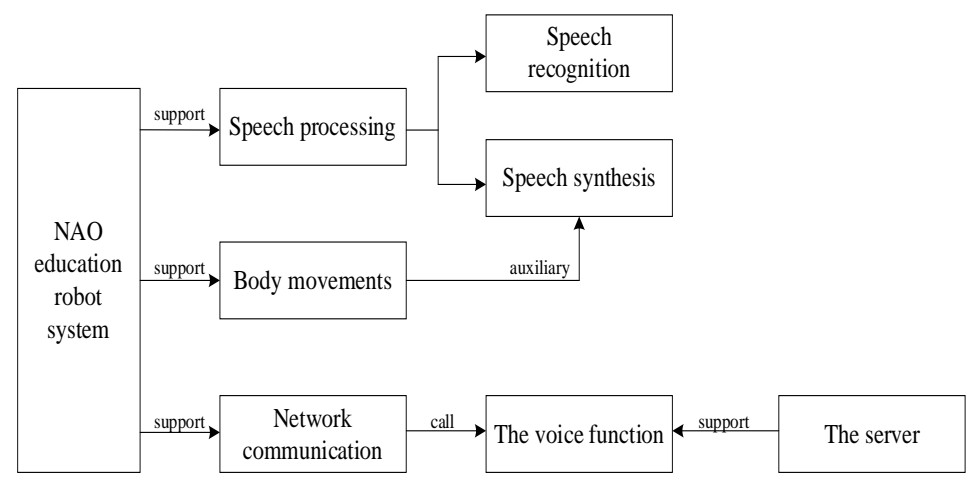

Fig. 1. Design framework of NAO educational robot system

\subsection{Key technology of educational robot design}

NAO robot: The development platform is NAO robot, which is developed by Aldebaran Robotic company in France. Figure 2 shows its entity diagram. The robot is $57 \mathrm{~cm}$ high and is equipped with infrared sensor, pressure sensor and ultrasonic 
distance sensor. In addition, the head and trunk of the robot are equipped with CPU. At the same time, two cameras and four microphones are included in the whole robot to capture and collect relevant information of users [10]. At the same time, the NAO robot is also equipped with multiple secondary development interfaces. Its built-in function modules can make the robot walk and communicate in different languages. In terms of development, the robot can support $\mathrm{C}++$, Java, Python and other mainstream development software.

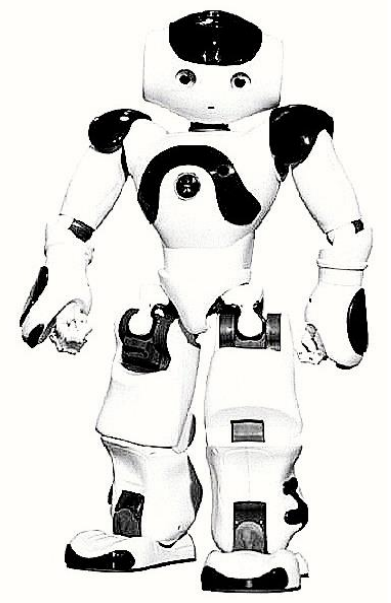

Fig. 2. Schematic diagram of NAO robot

Operating environment: The software environment is mainly divided into NAO robot environment and server environment. In the NAO robot environment, Python 2.8 software is mainly used to process the sound signal and call the interface. In the server environment, the core function of educational robot is realized by Java language experiment. The server is a $6 \mathrm{G}$ memory computer with Window10 operating system, and the server running program is Springboot framework [11]. NAO robot and server communicate in the same local area network using RESTFUL interface.

\subsection{Function realization of educational robot}

Vocabulary function: English vocabulary is the basis of English learning, and the amount of English vocabulary often directly affects the English level. However, memorizing vocabulary is a learning process which is very boring and easy to forget. In primary school English teaching, it is found that some students often lose interest in English learning because they cannot remember the words, and even fear difficulties and fear learning English [12]. Some students will produce the phenomenon of inaccurate English pronunciation, which will affect the follow-up English learning. The introduction of educational robot will solve this problem better. Innovative teaching mode will not only improve students' interest in learning, but also 
correct students' pronunciation habits. This requires that the educational robot must meet the function of vocabulary practice.

Figure 3 shows the vocabulary practice interactive function of the designed educational robot. It reveals that when the program starts, the user reads the words in front of the robot. If the machine can recognize the word, the word information will be passed to the server. If the speech synthesis is still unable to recognize, the word cannot be output normally. The implementation of vocabulary function needs the MySQL database. English word data of grade 6 are input into the database to store vocabulary information [13].

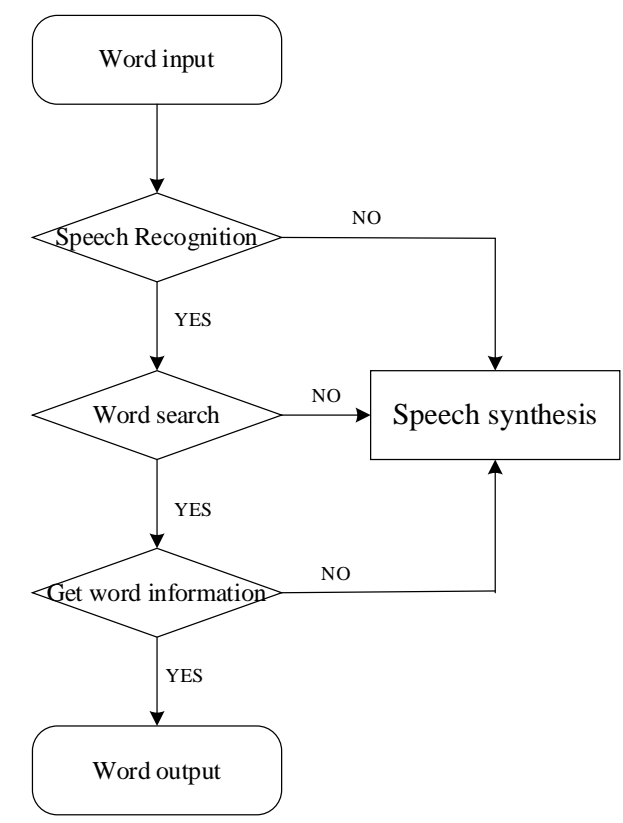

Fig. 3. Vocabulary function system framework

Role play function: In the practice of English teaching, the establishment of situational model will better promote the students to deepen the memory of relevant knowledge points, and achieve a deeper understanding of the English language. In traditional teaching, it is difficult to establish a good situational interaction due to the limitation of time. The unique human-computer interaction mode of educational robot can be used to build a good platform for interaction and communication, and establish good interaction with students, so that students can fully understand the meaning of the learning content in the situation [14]. In the role play function, the content in the grade 6 textbook is used as the corpus content, and the educational robot is used as the auxiliary teaching tool to help students fully understand the content. The dialogue content is set in units. Different dialogue contents are set in each unit. Students and robots play different roles to deepen the understanding of the text in role play [15]. 
The main implementation path under this function is divided into five steps. The details are as follows:

1. Users will choose what they want to learn according to the actual situation

2. The server determines the selected unit and extracts the corresponding information

3. The user selects the role according to the feedback information, and the server randomly determines whether the information selected by the student is legal or not

4. The server will automatically allocate learning content based on the information selected by users

5. The user and the robot start a dialogue to realize the role play function [16-18].

Free dialogue function: The function of free dialogue is mainly defined as follows. Without the help of other people, the robot takes the students' will as the leading factor to establish oral English learning situation and carry out appropriate oral English dialogue. Figure 4 shows the implementation framework of free dialogue. First, the user inputs the corresponding sound signal. The intelligent robot system performs corresponding speech recognition operation, and converts the sound signal into text signal. Then, the system comprehends the recognized text signals, performs acute dialogue comprehension according to the context and historical dialogue content, and finally performs speech synthesis to realize information output.

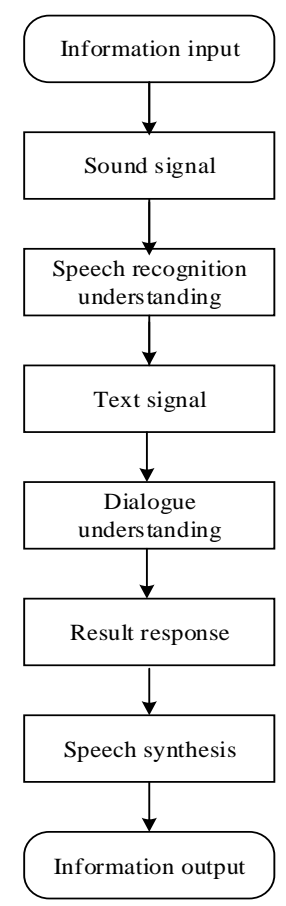

Fig. 4. System framework of dialog function implementation 


\subsection{Teaching result detection environment of educational robot}

In order to test the realization of various functions of educational robot, a set of test environment is built. Table 1 shows the details. Among them, the CPU is Intel Core i5-6500T, the system computer is a computer with 6GB memory and Windows 10 system, the database is MySQL 5.6, and the development tool is IntelliJ IDEA.

Table 1. System testing environment

\begin{tabular}{|l|l|l|l|}
\hline \multicolumn{1}{|c|}{ Name } & \multicolumn{1}{|c|}{ Model } & \multicolumn{1}{c|}{ Name } & \multicolumn{1}{c|}{ Model } \\
\hline CPU & Intel Core i5-6500T & RAM & 6GB \\
\hline \multirow{2}{*}{ System } & Windows 10 & Web server & $\begin{array}{l}\text { Nginx } \\
\text { Windows } \\
1.13 .3\end{array}$ \\
\hline Operating environment & JDK 1.8 & Database & MySQL 5.6 \\
\hline Development tools & IntelliJ IDEA & Front plug-in & Swagger 2.2.2 \\
\hline
\end{tabular}

\subsection{Design of robot teaching resources}

Based on the NAO educational robot, a series of teaching activities are designed. Figure 5 shows the specific process of teaching activities. Teaching activities are mainly divided into three parts: the pre-course part, the mid-course part and the late course part. First, at the beginning of the class, the teacher will use the educational robot to introduce the classroom content. In class, teachers and robots establish English learning scenarios together, and robots are used to teach vocabulary. In the middle of class, classroom interaction, question answering and group discussion are carried out. In the active atmosphere, students further deepen the impression of English learning. At the end of the class, the further consolidation exercises of words and knowledge points are carried out, and the classroom review is carried out to further deepen the students' impression of what have learned in this section.

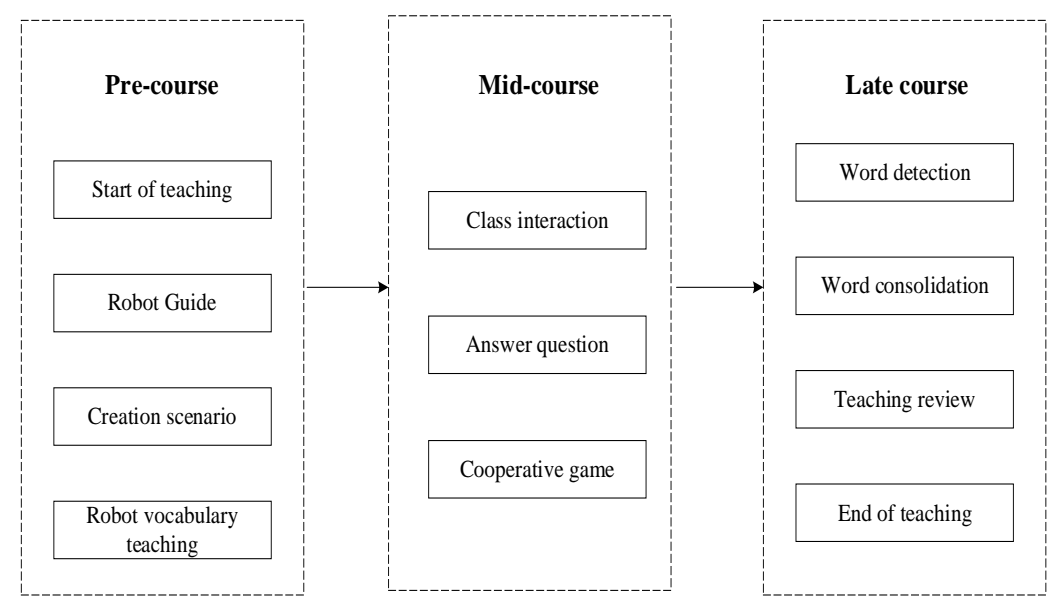

Fig. 5. Flow chart of curriculum design based on robot teaching resources 


\section{Results and discussion}

\subsection{Realization of vocabulary teaching function of educational robot}

Table 1 shows the interface test results of the vocabulary teaching function of the educational robot. First, the word is input as a parameter to the relevant path input program. When the word "book" is input, the system will automatically display the part of speech, meaning, example sentence and unit of the word. When the input parameter is not a word, such as the number "1", the system will automatically report an error and report that the output word does not exist. The experimental results show that the educational robot realizes the functions of vocabulary teaching.

Table 2. Test results of vocabulary teaching function

\begin{tabular}{|l|l|l|}
\hline \multicolumn{1}{|c|}{ Input } & \multicolumn{1}{|c|}{ Parameter } & \multicolumn{1}{c|}{ Output } \\
\hline Book & Property & Noun Verb \\
\hline & Interpretation & book \\
\hline & Example & the author of a book on politics \\
\hline & Unit & 3 \\
\hline 1 & Data & error \\
\hline
\end{tabular}

\subsection{Realization of role play function of educational robot}

Table 3 shows the test results of role play function. When the unit information, the role chosen by the learner and the number of conversations are input into the system, the system interface will automatically feedback the corresponding unit number, the language of the learner's role, the content of robot's speech and the number of conversations in this round.

Table 3. Test results of role play function

\begin{tabular}{|l|l|l|}
\hline & \multicolumn{1}{|c|}{ Parameter } & \multicolumn{1}{c|}{ Content } \\
\hline Input & Unit & 1 \\
\hline & Role & Linda \\
\hline & Index & 2 \\
\hline Output & Unit & 1 \\
\hline & Robot & Let's Begin \\
\hline & Student & Hi \\
\hline & Index & 2 \\
\hline
\end{tabular}

\subsection{Realization of free dialogue function of educational robot}

The interface test of free dialogue is completed by PUT. In the interface request path, relevant parameters are input to imitate the user's words, while the results returned from the interface will automatically output the robot's speech content and the state of dialogue. Table 4 shows the results. 
Table 4. Test results of free dialogue function

\begin{tabular}{|l|l|l|}
\hline & \multicolumn{1}{|c|}{ Parameter } & \multicolumn{1}{c|}{ Content } \\
\hline Input & Conversational & Hello, Jane \\
\hline Output & Conversational & Hi \\
\hline & Status & Success \\
\hline
\end{tabular}

\subsection{Application effect of educational robot in middle school English teaching}

In order to fully understand the specific application of educational robot in classroom, based on the completion of teaching objectives, the generation of teaching resources, the design of teaching content, the fluency of teaching links and the innovation of teaching process, the intelligent robot course is evaluated. The evaluation method is questionnaire survey, and the subjects are 5 English teachers and 5 students majoring in subject education in a university. The questionnaire is scored on a 5-point scale. The specific research contents are as follows.

Achievement of teaching objectives: The achievement of teaching objectives is mainly divided into four evaluation indicators, namely, the clear description of key and difficult points, the connection between teaching objectives and unit objectives, the teaching content considering the needs of most students, and the teaching objectives showing educational significance. The results of the questionnaire survey show that the scores of the four indicators are 4.4, 4.6, 4.2 and 5. Among them, the highest score is obtained in the educational significance of teaching objectives, which proves that this teaching method embodies the teaching idea of edutainment and has higher educational significance.

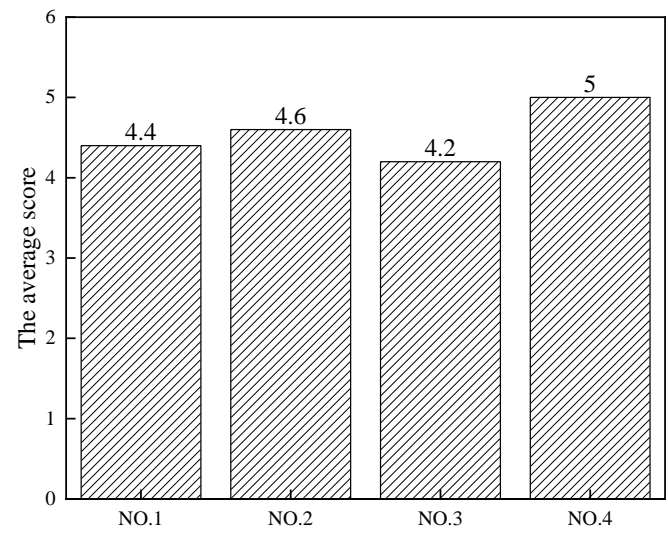

Fig. 6. Evaluation score of teaching objectives 
The generation of teaching resources: In the design of teaching content, the problem design mainly consists of the following points: the use of resources outside the textbook, the reasonable distribution of teaching resources, the novelty of teaching resources and the flexibility of teaching resources. The results show that the robot assisted teaching mode is a kind of education mode which can make full use of external resources and has high innovation.

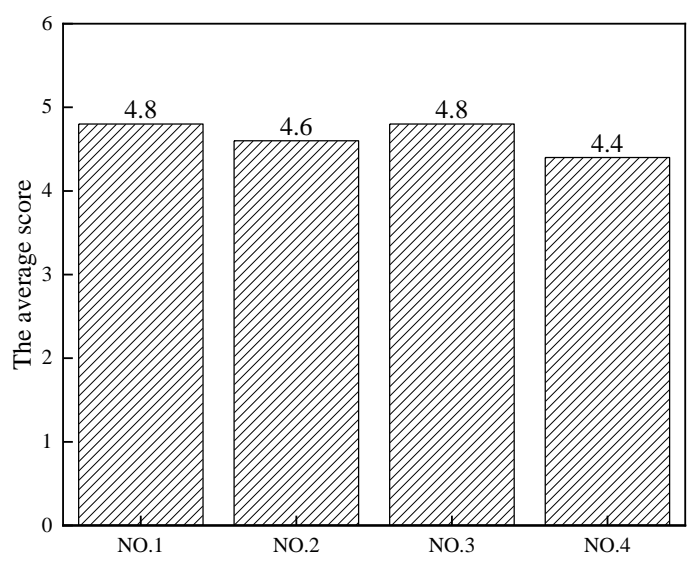

Fig. 7. Evaluation score of teaching resources generation

The design of teaching content: The evaluation indicators of teaching content design are as follows. Teaching content can be modified timely, teaching design can give full play to students' initiative, teaching design framework can be used for reference, and teaching content can adapt to different teaching environments and objects. The scores of the four indicators of teaching content evaluation are 3.8, 4.8, 4.2 and 4, respectively. The two indicators that teaching content can be modified and adapted to different objects are relatively low, which shows that the flexibility of teaching content is poor. As the classroom is mainly situational interaction, it is more suitable for the teaching of lower-grade students, but not suitable for English teaching of higher-grade students with self-control. Due to the robot teaching, the course is relatively fixed and cannot be adjusted flexibly. 


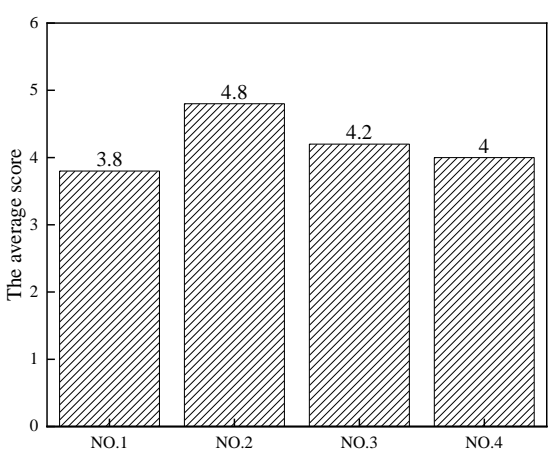

Fig. 8. Evaluation score of teaching content design

Fluency of teaching links: The evaluation of the fluency of teaching links mainly includes the following indicators. The teaching introduction is vivid, interesting, and close to life, the transmission of story situation is infectious, the situation design is interactive, the simulation experiment is intuitive and vivid, the consolidation link is closely connected with the teaching content, the teaching link is compact and orderly, and the situation setting is enlightening for students. In the evaluation, the scores of the interaction situation design and the intuitive and vivid simulation experiment are high, which further reflects the vivid and intuitive characteristics of robot assisted teaching in teaching practice.

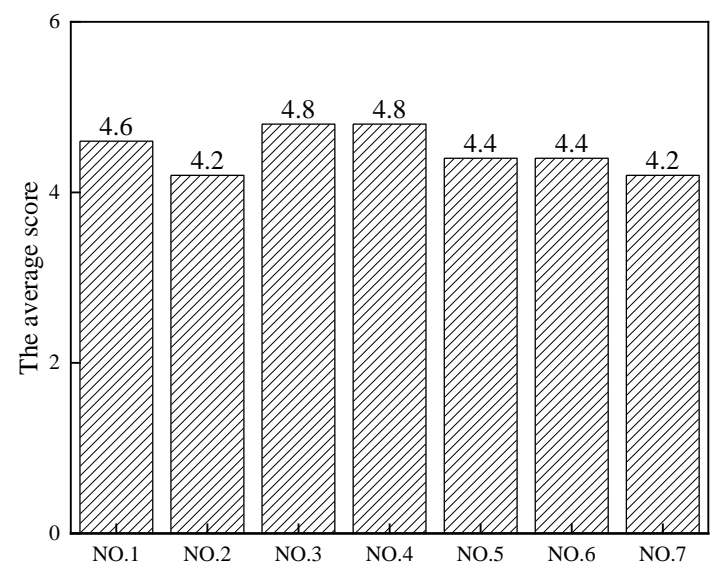

Fig. 9. Evaluation score of fluency in teaching process 
The innovation of teaching process: The evaluation indicators of innovation in teaching process are as follows. Teachers can mobilize the enthusiasm of students, teaching materials are close to students' life, students have time for autonomous learning, teachers can take into account the needs of individual students, there are various teaching activities, and teachers can use appropriate teaching tools. In this evaluation, the score of taking into account the needs of individual students is the lowest, which is mainly due to the limited class hours. It is often impossible for all students to participate in the situational dialogue activities, and the individual needs of some students are easily ignored in group discussion.

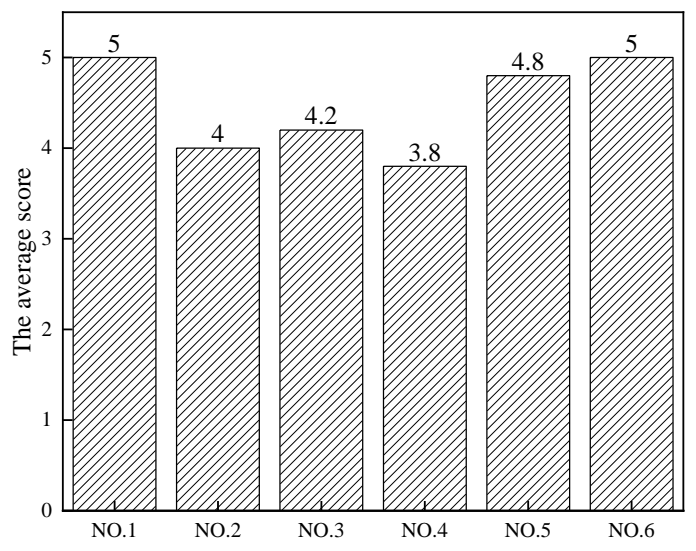

Fig. 10.Evaluation score of innovation in teaching process

Comprehensive score: The completion of teaching objectives, the generation of teaching resources, the design of teaching content, the fluency of teaching links and the innovation of teaching process are integrated. The average score is as follows. The basic score of 5 items reaches more than 4 . However, the score of the design of teaching content is the lowest, which needs to be further improved and optimized to improve the flexibility of robot assisted teaching. 


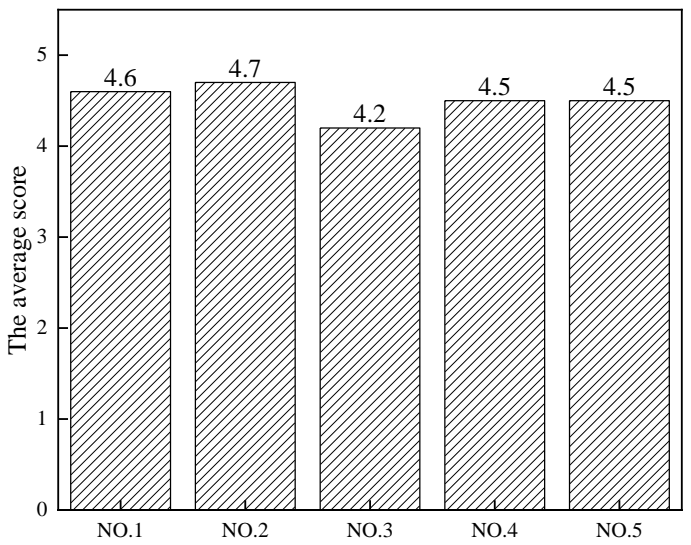

Fig. 11.Comprehensive score of teaching situation

\section{Conclusion}

Based on the self-designed NAO intelligent educational robot system, a set of intelligent robots assisted teaching curriculum is designed and used in a primary school. Good results have been achieved in English teaching in the primary school. The robot designed has the functions of vocabulary teaching, role play and free dialogue, which can meet the basic teaching requirements. At the same time, the questionnaire results of educational robot assisted teaching show that the score of the robot assisted teaching curriculum is more than 4 points in five evaluation indicators, including the completion of teaching objectives, the generation of teaching resources, the design of teaching content, the fluency of teaching links and the innovation of teaching process, which indicates that the curriculum has obvious advantages and is better than traditional English teaching. However, the flexibility of teaching content is not high, which needs to be further optimized and improved in the follow-up research.

\section{$5 \quad$ References}

[1] Simon, H., Hervé, (2019). The age of artificial intelligence in lung cancer pathology: Between hope, gloom and perspectives. Annales de pathologies, 39(2):130-136.

[2] Roll I, Wylie R. (2016). Evolution and Revolution in Artificial Intelligence in Education. International Journal of Artificial Intelligence in Education, 26(2):582-599. https://doi.org/ 10.1007/s40593-016-0110-3

[3] Dali Luo. (2018). Using decision models to enable better irrigation decision support systems. International Journal of Emerging Technologies in Learning, 13(8): 90-102.

[4] Fanwen Kong. (2020). Application of Artificial Intelligence in Modern Art Teaching. International Journal of Emerging Technologies in Learning, 15(13): 238-251. 
[5] Cuibi Yang, Shuliang Huan, Yong Yang. (2020). A Practical Teaching Mode for Colleges Supported by Artificial Intelligence. International Journal of Emerging Technologies in Learning, 15(17): 195-206. https://doi.org/10.3991/ijet.v15i17.16737

[6] Henkemans O. A. B., Bierman B. P. B., Janssen J., et al. (2017). Design and evaluation of a personal robot playing a self-management education game with children with diabetes type 4. International Journal of Human-Computer Studies, 106:63-76. https://doi.org/10.10 16/j.ijhcs.2017.06.001

[7] Nam, H. W. (2013), Development of Attention Improvement Robot Education Program. International Journal of Advancements in Computing Technology, 5(11):491-496. https:// doi.org/10.4156/ijact.vol5.issue11.61

[8] Arkadiusz G., Michal P., Aleksandra K. J. (2018), Implementation of an External Laser Scanner into Control System of the NAO Robot. IFAC PapersOnLine,2018, 51(6):231237. https://doi.org/10.1016/j.ifacol.2018.07.159

[9] Abhishek K. K., Dayal R. P., Saroj K. (2020), Dynamic Stabilization of NAO Humanoid Robot Based on Whole-Body Control with Simulated Annealing. International Journal of Humanoid Robotics, 17(3):29. https://doi.org/10.1142/s0219843620500140

[10] Andreasson R, Alenljung B, Billing E, et al. (2018). Affective Touch in Human-Robot Interaction: Conveying Emotion to the Nao Robot. International Journal of Social Robotics, 10(3):473-491. https://doi.org/10.1007/s12369-017-0446-3

[11] Suryotrisongko H, Jayanto D. P., Tjahyanto A. (2017). Design and Development of Backend Application for Public Complaint Systems Using Microservice Spring Boot. Procedia Computer Science, 124:736-743. https://doi.org/10.1016/j.procs.2017.12.212

[12] Wang, W. H. (2015). English as a Global Language in China: Deconstructing the Ideological Discourses of English in Language Education. System, 53:165-167. https://doi. org/10.1016/j.system.2015.07.010

[13] Veikkolainen T, Pesonen L J, Evans D. A. D. (2014). PALEOMAGIA: A PHP/MySQL database of the Precambrian paleomagnetic data[J]. Studia Geophysica et Geodaetica, 58(3):425-441. https://doi.org/10.1007/s11200-013-0382-0

[14] Grace Y. Q. (2016). The importance of English in primary school education in China: perceptions of students. Multilingual education, 6(1):1-18.

[15] Maria, Joh, Eun-Seon. (2012). Primary school parent-teachers' perceptions of primary English education and of their own children's English learning. Studies in English Education, 17(1):177-207.

[16] Garduño-Aparicio M, Rodríguez-Reséndiz J, Macias-Bobadilla G, et al. (2017). A multidisciplinary industrial robot approach for teaching mechatronics-related courses. IEEE Transactions on Education, 61(1): 55-62. https://doi.org/10.1109/te.2017.2741446

[17] Arvin F, Espinosa J, Bird B, et al. (2019). Mona: an affordable open-source mobile robot for education and research. Journal of Intelligent \& Robotic Systems, 94(3-4): 761-775. https://doi.org/10.1007/s10846-018-0866-9

[18] Cheng Y W, Sun P C, Chen N S. (2018). The essential applications of educational robot: Requirement analysis from the perspectives of experts, researchers and instructors. Computers \& education, 126: 399-416. https://doi.org/10.1016/j.compedu.2018.07.020

\section{$6 \quad$ Author}

Suo Huang is a Master and Lecturer. His research direction is computer network and computer language. He works in HuNan Urban Construction College.

Article submitted 2020-12-05. Resubmitted 2021-01-10. Final acceptance 2021-01-12. Final version published as submitted by the authors. 